\title{
El lugar de la poesía en el CUENTO: GUimARAes Rosa, GARCÍA MÁROUEZ Y ROBERTO BOLAÑO
}

\author{
Alberto Bejarano ${ }^{1}$ \\ Instituto Caro y Cuervo, Colombia.
}

\begin{abstract}
Resumen: En nuestro artículo proponemos hacer una lectura de literatura comparada sobre la relación entre poesía y cuento en tres grandes escritores latinoamericanos: Joao Guimaraes Rosa, Gabriel García Márquez y Roberto Bolaño. Nuestra pregunta se enfoca en reflexionar sobre el lugar de la poesía (como lectura, como búsqueda de sentido y como praxis de la escritura) en tres grandes narradores contemporáneos. Para ello nos centraremos en sus primeros libros de cuentos, explorando a través de archivos, el germen y la creación de un estilo con resonancias poeticas que caracteriza sus obras posteriores en monumentales novelas como Gran Sertón: Veredas, Cien años de soledad, El otoño del patriarca, Los detectives salvajes y 2666.

Palabras clave: Cuento; García Márquez y Roberto Bolaño; Guimaraes Rosa; literatura comparada; poesía.
\end{abstract}

Recibido: 14 de agosto de 2019

Aprobado: 20 de diciembre de 2019

\section{The place of poetry in the story: guimaraes rosa, garcía márquez and roberto bolaño}

\begin{abstract}
In our article we propose to do a comparative literature research on the relationship between poetry and short story in three great Latin American writers: Joao Guimaraes Rosa, Gabriel Garcia Márquez and Roberto Bolaño. Our question focuses on reflecting on the place of poetry (as a reading, as a search for meaning and as a praxis of writing) in three great contemporary narrators. For this we will focus on his first short story books, exploring through files, the germ and the creation of a style with poetic resonances that characterizes his later works in monumental novels like Gran Sertón: Veredas, One Hundred
\end{abstract}

${ }^{1}$ Doctor en Filosofía y estética de la Universidad París 8 con una tesis sobre Roberto Bolaño. Dirige la línea de investigación en "literatura comparada" en el Instituto Caro y Cuervo. Su último libro se titula: "Antología y estudio crítico de la revista de artes y literatura Espiral (1944-1954)", Editorial Sílaba- (Beca de investigación en literatura, Idartes), 2018. Profesor visitante en el doctorado de literatura de la Universidad federal de Minas Gerais en Brasil. Correo electrónico: alberto. bejarano@caroycuervo.gov.co. 
Years of Solitude, The Autumn of the Patriarch, The wild detectives and 2666.

Keywords: Comparative literature; García Márquez y Roberto Bolaño; Guimaraes Rosa; poetry; short story.

\section{Antecedentes}

Podríamos situar como antecedentes latinoamericanos comunes a los tres autores estudiados la emergencia de una mirada moderna y urbana en poetas y cuentistas como Borges y Mario de Andrade. Recordemos que Borges fue una influencia mayor en Gabo y Bolaño y Andrade en Guimaraes. Como lo menciona Assunção:

La poesía tal vez pueda acercar a Borges y Andrade en el espacio de la magia, de lo imaginario, de la crítica. En otros términos, "la mirada calidoscópica de la modernidad" (en la expresión de Raúl Antelo) se transforma, se intensifica en la mirada de dos poetas andariegos que cruzan dos escenarios urbanos modernos y periféricos en profundas transformaciones. De ese modo las diferencias pueden actuar como punto de partida para la aproximación y no para la separación... Pero es en el campo de la crítica, sobre todo en torno a una poética moderna (las vanguardias), donde ambos poetas se ubican en una arena común de lucha, donde se percibe una gran sintonía entre sus ideas. Ese diálogo permite identificar, aunque subterráneamente, un "espacio intelectual" crítico común. Sus ensayos críticos (y no solamente los textos poéticos) provocaron una verdadera revolución en la tradición literaria de sus respectivos países. (245-247)

Podríamos agregar que dicha revolución sobrepasó los límites nacionales, sobre todo en el caso de Borges. Como ha sido ampliamente reconocido, la tradición literaria latinomericana tiene profundas raices en el cuento, un género que en nuestra tierra se ha ido especializando y apartándose de las versiones europeas (en especial francesas) y norteamearicanas, lo cual responde a una tradición propia que tiene sus propios contornos. Para Pollman, por ejemplo:

"Cuando hablamos del cuento latinoamericano pensamos ciertamente más en autores contemporáneos, como Horacio Quiroga, Jorge Luis Borges, Joao Guimaraes Rosa, Augusto Roa Bastos, Julio Cortázar y otros. En las obras de estos autores se ve ejemplarmente reforzada la 
función que puede ejercer y que ha ejercido el cuento latinoamericano dentro del conjunto del sistema de los géneros literarios en el desarrollo de un autor y en el marco de la historia latinoamericana. Con Historia universal de la infamia (1934) nos acercamos al cuento puro, al cuento moderno, latinoamericano hasta lo mas intimo de sus estructuras narrativas... Gracias a los nombrados modelos externos y a la introducción del arte del cuento, la novela latinoamericana pudo convertirse en expresión de la propia relación con la realidad, lo que en la novela tradicional continua no era el caso." (209-211)

Nos interesa, sin embargo, recorrer el camino a la inversa: no ver la influencia del cuento en la novela latinoamericana como ya se ha estudiado a profundidad, sino rastrear las huellas de la poesía en el cuento. Para ello seguiremos el camino sugerido por varios investigadores en esa vía, como Alex Beigui, Anna Krauss o Alberto Bejarano, en la senda de tejer la relación entre narrativa y cuento en un plano performatico. Para Beigui:

A forma como o narrador de Rosa eleva as paredes ficcionais da narrativa revela um engenhoso quadro de instalação, sensações e modos de percepção do acontecimento imagético. Os recursos performáticos vão desde o engenhoso prolongamento das descrições e dos detalhes espaços-temporais (expansão), até o afunilamento da geografia cenográfica nos próprios corpos das personagens (contração). Verifiquemos, por ora, os principais mecanismos e combinações desse jogo performático presentes no conto, apontando, sempre que oportuno, os índices de performatividade presente nas estratégias do narrador performer. (2)

Se requiere retomar y prolongar la senda de estudios desde la poesía como los del investigador norteamericano James Alstrum sobre poetas colombianos como Mutis, Luis Carlos López y Darío Jaramillo Agudelo. La poesía es expresión de pérdida, melancolía, de desencuentro con el ser, de mutación en la modernidad. La pérdida puede representar lo irreparable y en muchas ocasiones conducir al suicidio. Nuestros tres escritores vivieron la separación, temporal o definitiva con sus países. No fueron exilio propiamente dicho en los tres (en Gabo y Bolaño, sí), pero sí experiencia de exilio interior. El exilio es una figura liminar de la existencia, es un ponerse-a-prueba 
en un sentido radical, como lo plantea el filósofo italiano Franco Rella en su libro Desde el exilio (2010). Lo primero que subrayamos en su lectura es la categoría de "desnudez" como una mirada que enfatiza la experiencia de fragilidad y vulnerabilidad del exilio que, no obstante, puede llevar a la persona a reconocerse como-un-otro, a devenir otracosa, a cuestionar su identidad, sus convicciones, su sensibilidad. Estar al desnudo, dice Rella, apunta a reconocerse en la máxima fragilidad posible, lo que puede llevar al sujeto a otros lugares de enunciación en los que surgen otras búsquedas estéticas. El lugar de la creación adquiere aquí un espacio absolutamente impensado en el que los encuentros y desencuentros con los nuevos mundos habitados, re-crean el país natal, por lo general en una deriva fantasmagórica intensa, y a la vez potencia una reconstrucción inédita para el sujeto. Estar desnudo es estar expuesto a la mirada de los otros, exponerse a ser visto como algo anómalo, como algo inquietante que pone a prueba al mismo tiempo la mirada del otro. Ver es ser visto. Estar desnudo es abrir una frontera, ir hacia el afuera, hacia lo abierto. Lo desconocido espera al otro lado de la barricada. Dejar el país natal, como Ulises en la epopeya clásica, significa aventurarse en tierras desiertas, en mundos inusitados en los que independientemente de la acogida o de la integración que se logre habrá siempre un desgarramiento, una herida incurable que no termina de sanar. El exilio es una sobre-exposición de la vida al desnudo, es una forma extrema de la nuda-vida en la que se lleva consigo una grieta que atraviesa el futuro. Rella insiste en que veamos el exilio como categoría de desnudez, como algo intrínseco a la experiencia moderna; por ello recurre a Baudelaire como el gran poeta-viajero que se sumergió en el fondo-de-sí mismo como un extranjero. De allí por ejemplo su poema bolañiano avant l'heure El Viaje:

"un oasis de horror en medio de un desierto de aburrimiento"

La modernidad implica vernos a nosotros mismos como extranjeros, como errantes sin patria natal, como confusos exploradores del abismo, como nómadas. Dicha desnudez, hay que insistir en ello, ha sido acentuada en el siglo XX en medio de las más graves tormentas políticas de la humanidad que llevaron al hombre a la inmolación de lo humano 
en los lager, campos de concentración, como lo ha estudiado Agamben. La diferencia entre el grito de Baudelaire y Rimbaud ("Hay que ser absolutamente modernos") y el tiempo pos-humanista que vivimos, tiene que ver con las consecuencias de una violencia totalizadora que convirtió el exilio en condición casi natural del hombre moderno, como puede apreciarse en autores como Imre Kertész o Thomas Bernhard, entre muchos otros.

Ser moderno es ser sobreviviente.

Para nuestros tres escritores, la poesía fue ese lugar de enunciación del mundo que derivó en sus primeros cuentos.

\section{La muerte en los cuentos tempranos de Guimaraes Rosa y Gabo}

Hay profundos paralelismos entre Gabo, Guimaraes Rosa y Bolaño. Los tres provienen de pequeños pueblos, Cordisburgo, Aracataca y la provincia de Valparaíso, en Chile. Los tres hicieron profundos viajes míticos, iniciáticos, uno al interior del Sertao, otro de las ciénagas, otro de los desiertos de Sonora. Gran Sertón: Veredas, Cien años de soledad y Los detectives salvajes (como lo han señalado múltiples críticos, como Candido, Angel Rama, Subirats, Gutiérrez Girardot, Carlos Pacheco, y otros), son las tres grandes novelas de la América profunda. Junto a Rulfo, Arguedas, Roa Bastos. Guimaraes Rosa, Gabo y Bolaño son los grandes poetas épicos americanos, trovadores e intérpretes de nuestra gran oralidad, de los archipiélagos que nos habitan, como lo llamara Glissant en varias de sus obras, en especial en Faulkner, Mississipi (2005): juglares de la oralidad.

En Gabo podemos verlo en sus primeros cuentos, luego publicados en el volumen Ojos de perro azul. Sobre todo "La otra costilla de la muerte", historia de un encuentro con lo inesperado y con la sensación de no encajar con un mundo nuevo (la ciudad), enfrentado a los espacios abiertos de la infancia y del paisaje caribeño que caracterizan la obra del premio nobel colombiano. En sus primeros cuentos es notable la sensación de desarraigo, bien sea de camino a un encuentro con lo fantástico (por la vía de Kafka y luego de Woolf) o a una cercanía con la muerte como presencia amenazadora. Esta idea la podemos constatar, por ejemplo, en las memorias del escritor, Vivir para contarla:

Las tardes de los domingos, cuando cerraban la sala de música, mi 
diversión más fructifera era viajar en los tranvias de vidrios azules, que por cinco centavos giraban sin cesar desde la plaza de bolívar hasta la avenida chile...lo único que hacía durante aquel viaje de círculos viciosos era leer libros de versos, quizá una cuadra de la ciudad por cada cuadra de versos, hasta que encendían las primeras luces en la llovizna perpetua. (310)

La muerte fue sin duda uno de los ejes narrativos del conjunto de la obra de García Márquez, comenzando desde su primer cuento. ${ }^{2}$ Es una temática muy estudiada, de manera temprana, por críticos como Jacques Gilard («[ ... ] Vemos en todo caso que la obra, que parecía oscilar entre dos concepciones del tiempo, tiene en realidad un eje más duradero: el del cadáver constante. Desde su primer cuento, desde septiembre 1947, García Márquez no ha prácticamente dejado de producir un inmenso discurso sobre la muerte». (Gilard 104)

En ese sentido nos apoyamos en visiones recientes de críticos como Gene Bell y Rubén Pelayo que apuntan a desmarcar la obra cuentística de Gabo de sus novelas. En otras palabras, el reto consiste en leer sus cuentos (en especial los de su primera época) sin buscar simples antecedentes para sus novelas posteriores. Dejar de ver el cuento como un laboratorio de la novela. De esta manera, podríamos tener un lente más claro para apreciar sus búsquedas, estilos y confrontaciones con sus lecturas. En palabras de Pelayo: "Si Gabriel García Márquez nunca hubiera publicado ninguna de sus novelas, de acuerdo con Gene H. BellVillada, sus cuentos le habrían dado un nicho en la historia literaria. Bell-Villada coloca a García Márquez junto con reconocidos maestros del cuento como Chekhov, Mann, Joyce, Cheever y Grace Paley. Sin duda a estos nombres podemos agregar los de Poe, Hemingway y Faulkner; y del mundo latino los nombres de Quiroga, Borges, Rulfo y Fuentes. En nuestra opinión, aunque de reciente factura, dos nombres que han ido ganando terreno en el interés mundial como cuentistas son los de Bolaño y Ruy Sánchez.” (52)

\footnotetext{
${ }^{2}$ Para un panorama completo sobre las rutas de interpretación de Gabo, ver el artículo de Juan Moreno, "La obra literaria garciamarquiana en y más allá de las cartografías impermeables", en Literatura: teoría, historia, crítica, No 8 (2006): 97-141, https://revistas.unal.edu.co/index.php/ lthc/article/viewFile/60139/57309
} 
En Guimaraes Rosa, la muerte puede ser un encantamiento o una condena. si pensamos por ejemplo en su cuento "El duelo", notamos que dos hombres se enfrentan a la muerte de manera distinta, uno, el que sabe primero que va a morir (sufre del corazón), no le teme a la muerte y se preocupa de arreglar sus asuntos pendientes. En cambio, el que no sabe que morirá pronto, en el momento de su muerte queda como suspendido. En Guimaraes Rosa hay un descubrimiento de un tiempo infinito que se confunde con el sertón. El tiempo se dilata y la muerte pareciera también suspenderse. Esta sensación de dilatación, de perderse en el paisaje como si este nunca terminara, como si el espacio marcara completamente el ritmo, es propia de sus cuentos. Ahora bien, ¿cómo operaria esta aparente ecuación en los primeros cuentos de Gabo? Lo primero que constatamos en sus cuentos tempranos es que el espacio es el espejo en el que se ven dos hombres que enfrentan la muerte de sus hermanos gemelos. En el primer cuento, "La otra costilla de la muerte", el mecanismo funciona como una mise en abîme, se narra el inicio en tercera persona y luego se pasa a la primera persona, como a través de un sueño. Al igual que en el cuento de Guimaraes Rosa, el paisaje es esencial para comprender lo que le ocurrirá a los personajes...

Iba en un tren (ahora puedo recordarlo) a través de un paisaje (este sueño lo he tenido frecuentemente) de naturalezas muertas, sembrado de árboles artificiales, falsos, frutecidos de navajas, tijeras y otros diversos (ahora recuerdo que debo hacerme arreglar el cabello) instrumentos de barbería. Detrás de un árbol estaba su hermano, el otro, su gemelo, el que había sido enterrado aquella tarde, gesticulando (esto me ha sucedido alguna vez en la vida real) para que hiciera detener el tren). (56)

Es fundamental retomar el contexto de escritura de los dos cuentos, señalado de manera precisa por Jacques Gilard:

"Mientras que el medio intelectual colombiano, a pesar de una cierta tendencia pesimista que se manifestaba de manera cíclica e inoperante, mostraba una gran autosatisfacción, de la que el suplemento literario de El Tiempo de Bogotá da un expresivo ejemplo, mientras que se proclamaba todavía que Bogotá era la Atenas suramericana y Colombia el país de los escritores, Eduardo Zalamea Borda era una de las pocas voces discordantes. Más y mejor que la inmensa mayoría de sus compatriotas, miraba fuera de las fronteras nacionales y entonces podía 
establecer comparaciones cuyo resultado era poco halagador para la literatura que se producía en el país. Lo decía en su columna diaria de $E l$ Espectador, "La ciudad y el mundo". Al mismo tiempo que El Espectador se abocaba a abrir una brecha en el cuasi-monopolio de El Tiempo, era una nueva concepción de la literatura lo que proponía el responsable de Fin de semana. Ciertamente, no era fácil atraer a los "grandes" nombres del momento: los cuentistas que citaba "Ulises" -ocupantes casi inamovibles de las páginas de El Tiempo y entre los cuales no debía apreciar sino a Octavio Amórtegui- no se habrían dignado publicar en una hoja tan modesta. "Ulises" lo sabía y su alusión no estaba exenta de ironía.” (Gilard 347).

Como tema común la muerte y la aproximación a lo fantasmal como revelación poética. En el cuento de Rosa, "La tercera orilla del río", es la relación padre e hijo; en el de Gabo, la de dos hermanos. En los dos casos se habla de orillas, costillas, fronteras en la muerte. No hay una influencia de uno en el otro, son escritos casi al mismo tiempo, paralelos corren como dos ríos. En el caso de Bolaño, un escritor de la generación siguiente, cuentos como "Sensini" o "El policía de las ratas" reflejan un espíritu fantasmal similar, con otros contornos más posmodernos.

Gabo y Rosa estuvieron en la misma esquina el día que cambió para siempre la historia de Colombia y de Bogotá, el 9 de abril de 1948, cuando mataron a Gaitán. Antonio Callado estuvo más cerca del joven Gabo, quien hacía sus primeros pasos en el periodismo y la literatura a una cuadra del crimen, en el periódico El Espectador, y Callado, como periodista cubría la conferencia panamericana (se alojaba en el Hotel Regina, quemado ese día, al frente del lugar del crimen). En el archivo Rui Barbosa se conserva la llave que Callado guardó, único vestigio de aquella ruina esplendorosa. Esa tarde Gabo perdió su primera máquina de escribir como lo cuenta en sus memorias y algunos manuscritos. Rosa perdió su equipaje y su máquina de escribir también en su primera visita a Bogotá en 1942. Mientras tanto Rosa, Rosa, el diplomático, se alejaba de la acción, y leía a Proust, como lo cuenta el mismo Callado. Ya había visto suficiente violencia en Europa durante la guerra.

Tanto en "La tercera orilla del río" como en "Páramo", otro cuento de Guimaraes Rosa, se trata de la historia de un personaje que deambula 
como un alma en pena, sin saber por qué. En el primero el hombre deja su casa y se retira al campo a dejarse vivir, o dejarse morir, no se puede saber del todo. Como una especie de Wakefiel tropical, neo barroco, como diría Sarduy. En el caso de "Páramo", el hombre persigue por la ciudad (Bogotá) un cadáver como una premonición siniestra del 9 de abril por venir. Rosa escribió y re-escribió este cuento a lo largo de los años, pero con seguridad parte de su experiencia del soroche la primera vez que vivió en las alturas de Bogotá en 1942, seis años antes del acontecimiento monstruoso. Mi interpretación de dirige a señalar que dicho cadaver es la prefiguración del cadaver insepulto de Gaitán.

\section{La muerte en el cuento "Muerte de Ulises" de Bolaño}

Este cuento fue publicado en el volúmen póstumo de cuentos de Bolaño, El secreto del mal (2007), y luego recogido en la nueva edición de los cuentos completos de Alfaguara en 2018. Fue escrito, según se dice en la nota editorial, en 1999. El cuento, "Muerte de Ulises", se concentra en una visita fugaz y fantasmagórica de Arturo Belano al D.F, en busca del rastro de su amigo Ulises Lima. Es una narrción corta (de seis páginas) en la que las huellas perdidas de Lima llevan a Belano a un extraño encuentro...con la muerte. Se trata de un relato con visos autobiográficos, sustentado en una visión de extrañamiento en la que Belano regresa al DF, veinte años después, algo que Bolaño no hizo. Es una especie de epifanía negativa que produce, sin embargo, una resonancia poética con la muerte y con los ecos de la poesía.

El inicio del cuento es este:

Belano, nuestro querido Arturo Belano, vuelve a la Ciudad de México. Han pasado más de veinte años desde la última vez que estuvo allí. El avión sobrevuela el DF y Belano despierta de golpe. La sensación de malestar que lo ha acompañado durante todo el viaje se hace más aguda. En el aeropuerto del DF tiene que tomar un enlace para Guadalajara, para la feria del libro, adonde ha sido invitado... el pasillo es un laberinto encristalizado...cuando por fin salle del pasillo la cola que se dirigía a tomar el enlace de Guadalajara ha desaparecido y Belano descubre, con una creciente sensación de alivio, que a él ya no le interesa viajar a Guadalajara ni participar en la feria del libro, sino quedarse en el DF. $\mathrm{Y}$ eso hace. Se dirige a la salida. Le miran el pasaporte y poco después está fuera, buscando un taxi. Otra vez en México, piensa. $(2018,563)$ 
El personaje, un Belano que no solo ya no es joven, sino que carga consigo una enfermedad crónica, liminar que lo llevará cuatro años después a la muerte, intenta reencontrarse con el DF de su juventud y con su amigo, el poeta Ulises Lima. Se dirige a la última dirección que conocía de él y tras unas breves peripecias, entra en contacto con tres jóvenes que fueron los últimos discípulos de Lima en el DF. La visión del personaje está plagada de melancolia y de un contraste notable entre los recuerdos y las impresiones borrosas del presente: "Belano cierra los ojos, como cuando vivía allí y cerraba los ojos, pero ahora está tan cansado que los abre casi de inmediato y la ciudad, su vieja ciudad de la adolescencia, se despliega gratuitamente para él. Nada ha cambiado, piensa, aunque sabe que todo ha cambiado." $(2018,563)$

Nada ha cambiado, pero todo ha cambiado, nos sugiere Belano. A medida que se acerca al último departamento de Lima, su sensación de extravío va en aumento y se produce un sin sabor creciente y una mezcla de emociones propias del universo bolañiano, con respecto a su famosa frase: "hay momentos para escribir poesía y hay momentos para boxear". Justamente esto es lo que parece estar a punto de ocurrir en el relato:

Ese dep está vació, dice el joven. Ya lo sé, dice Belano. ¿Entonces por qué tocas, güey?, dice el joven. Belano lo mira a los ojos y no contesta. La puerta se abre del todo y el joven si pelos sale al pasillo. Es gordo y está vestido solo con unos bluejeans muy anchos, sujetos con una correa antigua. La hebilla es grande, metálica, aunque la barriga del joven la oculta en parte. ¿Quieres pegarme?, piensa Belano. Durante un instante ambos se estudian. Nuestro Arturo Belano, queridos lectores, tiene ya cuarentaiséis años y está mal, como todos sabéis o deberíais saber, del hígado, del páncreas e incluso del colón, pero aún saber boxear y sopesa con la mirada la figura voluminosa que tiene enfrente. Cuando vivió en México se peleó muchas veces y nunca perdió, lo que ahora le parece increible. $(2018,566)$.

La poesía nómada de Lima es de contagio, de mundo, de inmundicias, de fronteras, de golpes, de enfermedades, de vida y muerte, como podemos observarlo una y otra vez en sus poemas, recogidos póstumamente. 
"la poesía sale de mi boca

A todo tranco de gerundio

A todo flujo de agua potable

A todo virus luminoso

A toda capacidad de contagio

Así va la poesía/

\& para ella

No tengo sino alabanzas" (Santiago, 51)

"Acaricio mi próximo suicidio

Como mi poema más cortopunzante

Como mi poema más perfecto" (Santiago, 110)

Para Bolaño, la escena del cuento que comentamos aparece para nosotros bordeada por este poema de Santiago (Lima), ya prefigurada, -como en tantas otras ocasiones de su obra-, en su poesía, en este caso, en el poema Atole aparecido en La Universidad desconocida, pero publicado originalmente en 1994 en Los perros románticos:

"Vi a Mario Santiago y a Orlando Guillén

Los poetas perdidos de México

Tomando atole con el dedo

Borrachos y drogados como escritos con sangre

Ahora desaparecen por el esplendor geométrico

Que es el México que les pertenece

El México de las soledades y los recuerdos

El del metro nocturno y los cafés chinos

El del amanecer y el del atole" $(2007,365)$

El final del cuento nos situa en la presencia fantasmagórica de Lima, del DF perdido de la juventud de Bolaño y en especial en la resonancia de la poesía como resto, como supervivencia extrema de lo vívido y de lo esfumado. Justamente así es el final del cuento:

"Lo que sigue es caótico y sentimental: los gordos le informan que ellos fueron los últimos discípulos de Ulises Lima (lo expresan así: dis- 
cípulos). Le hablan de su muerte, atropellado por un coche misterioso, un Impala negro, y le hablan de su vida, una sucesión de borracheras sin cuento en las cuales fue dejando su impronta, como si los bares y los cuartos en donde Ulises Lima se sintió mal y vomitó fueran los voluminosos volúmenes de su obra completa. También, sobre todo, hablan de ellos mismos: tienen un grupo de rock llamado El ojete de Morelos y tocan en discotecas de los suburbios del DF. Han grabado un disco que las emisoras de radio oficiales se niegan a poner debido al contenido de sus letras. Las pequeñas emisoras, por el contrario, están todo el día pinchando sus canciones. Somos cada día más famosos, dicen, pero seguimos siendo rebeldes. La senda de Ulises Lima, dicen, las balas trazadoras de Ulises Lima, la poesía del más grande poeta mexicano." $(2018,568)$.

La poesía es pues figura liminar del vómito de Lima, y es la senda, el trazo disuelto de su vida y obra en un grupo de rock marginal de un suburbio del DF que suena en emisoras pequeñas. Como si Bolaño nos dijera que la poesía es el resto, lo confuso, lo perdido, lo no clasificado, lo que escapa a las distinciones y panteones. En otros términos, este cuento es una oda a la poesía como muerte-en-vida, en el caso de Lima y como nomadismo total en lucha con la muerte. La escena nos recuerda uno de los momentos cruciales de Los detectives salvajes, cuando la banda de jóvenes poetas se dispone a escapar hacia Sonora tras la senda de otra poeta mítica, Cesárea Tinajero, hacia el final de la tercera parte:

Escuché que Belano y Lima hablaban de un poeta que escapaba de un campo de batalla, sin importarle la vergüenza y el deshonor que tal acto acarreaba, al contrario, vanagloriándose de él. Y entonces yo empecé a soñar con un tipo que atravesaba un campo de huesos y el tipo en cuestión o tenía rostro o al menos yo no podía verle el rostro porque lo observaba desde lejos. Yo estaba bajo una colina y apenas había aire en ese valle. El tipo iba desnudo y tenía el pelo largo y al principio pensé que se trataba de Arquíloco pero en realidad podía ser cualquiera. Cuando abrí los ojos aún era noche cerrada y ya habíamos salido del df. $(1998,561)$ 


\section{Conclusión}

La mirada de Guimaraes Rosa rastrea la niebla...el sertón, el soroche: la muerte

La mirada de Gabo rastrea la zona bananera, la ciénaga, el bochorno: la muerte

La mirada de Bolaño rastrea el D.F, el desierto de Sonora, los impalas: la muerte

En nuestra reflexión nos hemos centrado en el rastreo de las huellas de la poesía, como artefacto de lectura y de experiencia vital, en una serie de cuentos de los escritores latinoamericanos Guimaraes Rosa, García Márquez y Bolaño. Más allá de las diferencias notables de estilo, sobre todo entre los dos primeros y Bolaño, nos ha interesado centrarnos en la interacción del cuento con la poesía y en identificar de qué forma las presencias fantasmagóricas sobre el pasado, el viaje y la muerte, acompañan intrínsecamente los relatos.

\section{Referencias}

Assunção, Ronaldo. "Mario de Andrade y Jorge Luis Borges poesía urbana y vanguardia en la década de 1920", variaciones borges 19, 2005, Digital. https://www.borges.pitt.edu/sites/default/files/1913.pdf. Consultado el 5 de agosto de 2019

Beigui, Alex. "Guimarães Rosa ou o narrador como performer". Revista Recorte, UNINCOR V. 10 - N. 2 (julho-dezembro/2013), Digital. https:// dialnet.unirioja.es/servlet/articulo? codigo $=4791976$. Consultado el 4 de agosto de 2019

Bolaño, Roberto. Los detectives salvajes. Barcelona: Anagrama, 1998. Impreso.

Bolaño, Roberto. La universidad desconocida. Barcelona: Anagrama, 2007. Impreso.

Bolaño, Roberto. Cuentos completos. Bogotá: Alfaguara, 2018. Impreso.

Garcia Marquez, Gabriel. Vivir para contarla. Bogotá: Norma, 2002. Impreso. García Márquez, Gabriel. Ojos de perro azul. Bogotá: norma, 2004. Impreso.

Gilard, Jacques. «García Márquez et la mort annoncée», Co-tates, 6 (1983), p. 72 (trad. de M. Z.), en Gilard, Jacques, Eduardo Zalamea Borda, descubridor de García Márquez, Literatura: teoría, historia, crítica, núm. 8, 2006, pp. 339-351. Impreso.

Glissant, Édouard. Faulkner Mississipi, FCE : México, 1996. Impreso. 
Moreno, Juan. "La obra literaria garciamarquiana en y más allá de las cartografias impermeables", en Literatura: teoría, historia, crítica, No 8 (2006): 97-141. Digital. https://revistas.unal.edu.co/index.php/lthc/article/ viewFile/60139/57309

Pelayo, Rubén. "La magia del amor, los horrores de la muerte y otros temas en los cuentos de Gabriel García Márquez". Boletín Redipe, ISSN-e 22561536, Vol. 6, № $.10,2017$, págs. 49-62. Consultado el 2 de agosto de 2019. Digital.

Pollman, Leo. "Función del cuento latinoamericano". Revista iberoamericana, no 118, enero de 1982, Digital. https://revista-iberoamericana.pitt.edu/ ojs/index.php/Iberoamericana/article/view/3692/3863. Consultado el 8 de agosto de 2019.

Rella, Franco. Desde el exilio. Buenos Aires: La cebra, 2010. Impreso.

Santiago, Mario. Jeta de santo. México: FCE, 2008. Impreso.

Zapata, Mónica. "Peregrinaciones hacia lo grotesco en tres cuentos de García Márquez”. Letras. 1409-424X, Vol. 2, №. 29-30, 1993, págs. 101-112. Consultado el 5 de agosto de 2019. Digital. 